\title{
La construcción discursiva del populismo autoritario
}

Adriana Bolivar

Universidad Central de Venezuela

\section{Introducción}

Como respuesta al colapso de las democracias, al desprestigio de los partidos tradicionales, la corrupción, el fracaso de las políticas macro-económicas globales, los movimientos migratorios masivos, entre otras cosas, han surgido nuevos populismos en Europa y en América Latina (Arenas 20II; De la Torre 2007, 20I0, 20I6; Moffit 20I6) que llaman la atención por su supuesto carácter de "excluyentes" o "incluyentes" $(\text { Wodak 20I } 5)^{\mathrm{I}}$. Debido a que la relación entre democracia y populismo es muy estrecha y ambivalente, el problema que nos interesa a científicos sociales y lingüistas es averiguar los efectos de los populismos extremos en la calidad de las democracias. De ahí mi interés por el tema del autoritarismo, en especial cómo se ha presentado en la dinámica socio-política latinoamericana a partir de los cambios que se iniciaron en 1999 liderados por Hugo Chávez en Venezuela y seguidos por otros presidentes de América Latina (Evo Morales en Bolivia, Rafael Correa en Ecuador).

Desde la perspectiva de Paulo Freire, el filósofo y educador brasileño, quien cree en la dialogicidad como práctica de la libertad, el problema residiría en que los populismos autoritarios comparten una cultura antidialogicista porque, como él mismo dice, "Hablar de

${ }^{1}$ Las comillas se explican porque en el caso de los populismos de derecha se dice que excluyen a inmigrantes o minorías étnicas, mientras que a los de izquierda se les considera incluyentes porque supuestamente toman en cuenta al pueblo menos favorecido económicamente.

Cómo citar este capítulo:

Bolívar, A. 20I9. "La construcción discursiva del populismo autoritario". In: Françoise Sullet-Nylander, María Bernal, Christophe Premat \& Malin Roitman (eds.). Political Discourses at the Extremes. Expressions of Populism in Romance-Speaking Countries. Stockholm Studies in Romance Languages. Stockholm: Stockholm University Press, pp. I3-33. DOI: https://doi.org/I0.I6993/bax.b. License: CC-BY 
democracia y callar al pueblo es una farsa. Hablar del humanismo y negar a los hombres es una mentira" (Freire 20II: III). Freire propuso la anti-dialogicidad y la dialogicidad como matrices de teorías de acción cultural antagónicas: la primera sirve a la opresión; la segunda a la liberación. Según él, la cultura anti-dialógica se basa en la conquista, la división, la manipulación y la invasión cultural ${ }^{2}$, mientras que la cultura dialógica favorece la colaboración, la unión, la organización y la síntesis cultural.

En ese trabajo plantearé, desde mi perspectiva como lingüista y analista del discurso, que el populismo autoritario se construye simultáneamente en la acción política y discursiva. Lo que está en juego es la libertad de participar en el diálogo democrático al que todos los ciudadanos tienen derecho, y la gran pregunta parece ser si los nuevos populismos tienen o no el potencial para construir versiones más incluyentes de la democracia (Moffit 20I 5). La respuesta no es fácil porque tanto los populismos de derecha como de izquierda contienen rasgos democráticos y no democráticos, como veremos más adelante.

Como un caso de anti-dialogicismo en la política, en el que el populismo no ha contribuido a mejorar la democracia, me referiré al populismo venezolano reciente que ha sido denominado 'autoritario' y 'militarista' por historiadores, politólogos y científicos sociales venezolanos (Arenas 2007, 20I 2; Carrera Damas 20I I; Madriz 2008) y como 'autoritarismo participativo competitivo' por científicos políticos de otras latitudes que se hacen preguntas clave sobre la experiencia fallida del Socialismo del Siglo 2I en Venezuela, y que invitan a la reflexión, tal como lo plantea, por ejemplo, Mainwaring (20I2):

Contemporary Venezuela raises fascinating questions about the collapse of a highly institutionalized party system and the erosion or breakdown of what had been the third-oldest democracy outside of the advanced industrial democracies. What accounts for these stunning developments? What can we learn from them? These issues go to the core of important developments in Latin American politics, and they are major issues for comparative political scientists beyond Latin America (p. 955).

\footnotetext{
2 Aunque en la teoría de Freire la dominación cultural se refiere más bien a la cultura neo-liberal o capitalista en general, en el caso de Venezuela se trata de un país que ha estado sometido primero a la dominación cultural española, luego a la norteamericana debido a lazos comerciales en torno al petróleo y, desde I999, a la cubana, ya que Fidel Castro fue el principal mentor de Hugo Chávez.
} 
Mi interés particular en este trabajo es mostrar cómo un sistema democrático bipartidista que estuvo estable por 40 años pasó a ser no democrático en un periodo relativamente corto de su historia debido, en gran parte, al deterioro en la calidad del diálogo entre el gobierno y el pueblo. Presentaré primero un breve resumen del contexto político, luego examinaré algunos aspectos relevantes para el estudio del populismo y las democracias, con un resumen de mi aproximación teórica, y cerraré con ejemplos de las estrategias políticas y discursivas que condujeron a la transformación de la democracia representativa en una democracia revolucionaria.

\section{El contexto}

El giro hacia una democracia radical fue iniciado por Hugo Chávez en 1999 con la intención de mejorar la democracia representativa para hacerla "participativa" y "protagónica", como quedó plasmado en la nueva Constitución venezolana aprobada al inicio de su primer gobierno. El año 1999 es importante porque se introdujo una doble ruptura en la historia política venezolana ya que, por un lado, se pasó de una democracia representativa (I958-I998) a una revolucionaria y, por otro, se pasó de un estilo en que se buscaba el consenso y la alternancia de partidos tradicionales (Acción Democrática, AD, y Democracia Cristiana, COPEI) al conflicto como método del partido dominante en el gobierno (Partido Socialista Unido, PSUV). Durante el gobierno de Chávez, apoyado por Fidel Castro desde Cuba, se polarizó el país entre Gobierno y Oposición y también América Latina entre Bolivarianos y no Bolivarianos (Bolívar 2013; Chumaceiro 2003). La influencia de Hugo Chávez llegó a España, a través del grupo Podemos, y hasta Grecia a través del partido Syriza. Su gobierno duró I 4 años, desde I999 hasta su muerte en 2013.

Gracias a la renta petrolera, Chávez pudo desarrollar programas sociales para el pueblo, especialmente entre 2003 y 2008 , pero debido a las expropiaciones, la falta de inversión, la corrupción, la violencia, y la caída de los precios petroleros, cuando su sucesor, Nicolás Maduro, llegó al poder el país ya no disponía de los fondos que le garantizaban continuar con dichos programas. Maduro no tiene el carisma de Chávez y la población se volvió más crítica y más exigente en cuanto al cumplimiento de las promesas. En este momento, en el año 2018, el país atraviesa una de las mayores crisis de su historia republicana en lo económico, lo social y lo moral, y la ciudadanía se ha declarado 
en desobediencia civil ${ }^{3}$. A Maduro se le hace responsable de una crisis humanitaria sin precedentes, que implica hambre, escasez de medicinas, mortalidad infantil, violación de derechos humanos, y el mayor movimiento migratorio en la historia reciente del continente ${ }^{4}$.

Desde el punto de vista político, en la situación actual, Venezuela no puede considerarse una democracia, al menos no desde la perspectiva procedimental (procedural) de Mainwaring (20I2) quien la define como "a political regime with free and fair elections for the executive and legislature, nearly universal adult enfranchisement in the contemporary period, the protection of political rights and civil liberties, and civilian control of the military" (p. 959). En consecuencia, podemos afirmar que el gobierno de Chávez cumplió con realizar elecciones, pero incorporó a los militares al poder y militarizó la política (Rivas Leone 20I2). Mientras que, en el caso del Presidente Maduro, a partir de 20I4, no se cumplen ninguna de las condiciones porque no se ha respetado la Constitución, no hay separación de poderes, se ha desconocido a la Asamblea Nacional, que en 2015 dio a la Oposición una mayoría absoluta, y no se han realizado elecciones de ningún tipo desde ese momento. El destino de los políticos opositores es estar inhabilitados, en el exilio o en la cárcel.

Para algunos la revolución es un fracaso económico, pero un gran logro emocional porque Hugo Chávez logró establecer un fuerte lazo con el pueblo y convertirse en un héroe divino como Simón Bolívar, el Libertador de América (Pino Iturrieta 2003). Para otros, significa el surgimiento de un nuevo fascismo y la transformación de la democracia en un estado mafioso (Chaplin 20I4), debido a que es diferente a otros países por la riqueza que le ha dado el petróleo. Aunque en gobiernos anteriores, Venezuela también se benefició de la renta petrolera, Chávez mismo y el Chavismo son vistos como un sub-producto político del petróleo, porque le permitió lograr el control absoluto del poder para

3 Venezuela fue noticia en todo el mundo en el año 2017 por las marchas diarias y los enfrentamientos entre jóvenes desarmados a quienes la Guardia lanzaba bombas y perdigones. Lo que se inició en la capital continuó en las provincias con gran violencia. Las protestas decían "No a la dictadura" y reclamaban por la escasez de alimentos y de medicinas, así como por la alta criminalidad. Véase la lista de presos y detenidos en el Foro Penal Venezolano: https:/foropenal.com/presos-politicos/ lista-publica actualizada 30 de abril de 20I7. Consultada el 25 de mayo de 2017.

4 Véase: “2.3 millones han huido de Venezuela en los últimos años”. https://www.bbc. com/mundo/noticias-america-latina-452624II. 22 de agosto de 2018. Consultado 22 de octubre de 2018 
llevar a cabo transformaciones sociales y políticas, que no fueron del todo positivas, como lo expresa Mires (20I4):

Venezuela under Chávez destroyed national industries and social organizations such as trade unions. Chavism was converted into a national religion, a corrupt state party, or to put it in other words a mafia organization supported by the oil income. Chavism, to some extent, is a political sub-product of oil (....) Chávez was able to establish nearly total control of the mass media and the judicial branch which functioned to prosecute and terrorize people that were viewed by the mafia as enemies. (p. viii)

A Maduro se le menciona abiertamente como "dictador" y a su gobierno como una "narcodictadura". Recientemente ha sido denunciado por varios países (Argentina, Chile, Colombia, Paraguay, Perú y Canadá) ante la Corte Penal Internacional por acusaciones relacionadas con violación a los derechos humanos y abusos cometidos en Venezuelas. Maduro ha profundizado el anti-diálogo con los opositores y con los miembros de su propio partido, lo que está llevando a mostrar cada vez más "un chavismo crítico" y una mayor disidencia interna.

\section{Los rasgos políticos y discursivos del populismo}

Podemos estar de acuerdo inicialmente en que hay ciertos rasgos que se repiten en todo populismo, particularmente: a) la presencia de un líder carismático en algún momento crítico, b) el pueblo como víctima de su pasado, c) la construcción de un enemigo a quien se culpa de todos los males, y d) el apelativo a las emociones más que a las razones (Bobbio, Matteuci \& Pasquino I983; Charaudeau 2009; Chumaceiro 20Io; De la Torre 20I0; Wodak 20I 5, entre otros).

Aunque actualmente las líneas entre la derecha y la izquierda tradicional, y también entre las izquierdas (Petkoff 2013) están borrosas, algunos adjudican características especiales a los populismos de derecha y de izquierda. Por ejemplo, Wodak 2015 (pp. 20-22) presenta nueve rasgos característicos de los populismos de derecha en Europa, muchos de los cuales también podrían aplicarse a los de izquierda. Mientras que Mouffe (20I6) defiende a los populismos de izquierda si se conciben de otra forma que requiere establecer otro tipo de hegemonía, la de un

5 Véase para mayores detalles ¿En qué consiste la solicitud de seis países ante la CPI de investigar a Venezuela? https://www.nytimes,com/es/2018/o9/o6/venezyuela. la.haya-cpi/ consultada 22 de octubre de 2018. 
colectivo, sin subordinar a los movimientos de masa. No obstante, el problema sigue siendo que el discurso de los populismos de derecha y de izquierda contiene rasgos democráticos y no democráticos, como se resumen en la Tabla I más abajo.

Tabla 1. Rasgos percibidos como democráticos y no democráticos del discurso populista (basado en Moffit 201 5 ; adaptado según Bolívar 20I5, 20I6, 20I8):

\begin{tabular}{|c|c|}
\hline Rasgos discursivos democráticos & Rasgos discursivos no-democráticos \\
\hline \multirow{2}{*}{$\begin{array}{l}\text { I. El lenguaje es accesible. La } \\
\text { política se hace más fácil de } \\
\text { comprender para el pueblo. } \\
\text { 2. Se usa el lenguaje de "la gente } \\
\text { común". El líder habla como el } \\
\text { pueblo. }\end{array}$} & $\begin{array}{l}\text { I. Las minorías y los que no siguen al } \\
\text { líder son vistos como "enemigos" }\end{array}$ \\
\hline & $\begin{array}{l}\text { 2. El pueblo se concibe como una } \\
\text { unidad homogénea que engloba } \\
\text { solo a una parte de la totalidad del } \\
\text { pueblo. }\end{array}$ \\
\hline \multirow{3}{*}{$\begin{array}{l}\text { 3. Incluye a grupos que han } \\
\text { estado excluidos y los legitima } \\
\text { como actores políticos (los más } \\
\text { pobres). } \\
\text { 4. Expone las fallas de los sistemas } \\
\text { democráticos de la actualidad. } \\
\text { 5. Expresa reiteradamente su } \\
\text { amor incondicional por el pue- } \\
\text { blo excluido }\end{array}$} & $\begin{array}{l}\text { 3. Los que no forman parte del pueblo } \\
\text { son considerados "ilegítimos". }\end{array}$ \\
\hline & $\begin{array}{l}\text { 4. Se tiene una visión simplificada de } \\
\text { la política como guerra entre "el } \\
\text { pueblo" y sus enemigos. }\end{array}$ \\
\hline & $\begin{array}{l}\text { 5. Se buscan chivos expiatorios } \\
\text { culpables de todos los males (los } \\
\text { inmigrantes, la oligarquía, el } \\
\text { capitalismo) }\end{array}$ \\
\hline \multirow{2}{*}{$\begin{array}{l}\text { 6. Resuelve problemas al pueblo } \\
\text { de manera inmediatista. }\end{array}$} & 6. Tendencia al personalismo extremo \\
\hline & $\begin{array}{l}\text { 7. Abuso de poder, concentración } \\
\text { de poder y movimiento hacia el } \\
\text { autoritarismo. }\end{array}$ \\
\hline
\end{tabular}

\subsection{El diálogo como condición de la democracia: el análisis interaccional}

He planteado en varias publicaciones que el diálogo es una condición esencial de la vida humana, de la política y, por ende, de la democracia (Arendt I958; Bolívar 2007a, 2007b, 2010, 2013), y he propuesto un enfoque que denomino análisis interaccional del discurso para diferenciarlo de otros análisis que ponen mayor énfasis en la representación del conocimiento o aspectos socio-cognitivos (como van Dijk, I993, 2002, 2005; Wodak, 200Ia, 200Ib; Chilton y Schäffner 2002, y otros) 
o de quienes lo conciben desde una perspectiva normativa o utópica (ver por ejemplo Fairclough 2000, 2003).

En mi análisis se articulan la lingüística, el análisis de la conversación, la socio-pragmática cultural y la ciencia política, y el foco está en los participantes en el diálogo como responsables de mover la política. Distingo entre diálogo en situaciones específicas (el micro-diálogo) y el macro-diálogo que se examina en la dimensión diacrónica con la participación de los ciudadanos que apoyan los cambios o se resisten e ellos. Esto quiere decir que la perspectiva histórica es fundamental para evaluar los cambios introducidos por los actores políticos en el discurso (Bolívar 20I0, 20I3, 20I6). Igualmente, es importante estudiar la afectividad en el lenguaje, que se manifiesta discursivamente a través de la vinculación afectiva positiva (con el pueblo) y de la vinculación afectiva negativa (con los "enemigos") (Bolívar 20I 5, 20I6; Nieto y Otero 2007, 20I2), particularmente en el discurso populista venezolano que, históricamente y gracias al petróleo, ha construido un imaginario de democracia en el que el líder tiene el rol de benefactor y el pueblo el de beneficiario, porque recibe dádivas o regalos que crean un estrecho lazo emocional de gratitud y lealtad (Bolívar 20I8, Charaudeau 2000; Madriz 2008).

Desde el punto de vista metodológico, el análisis interaccional es motivado por los conflictos en eventos, basados o dirigidos por corpus de datos recogidos en interacciones concretas, en diálogos de diferentes tipos, institucionales o no, en un continuum de lo micro a lo macro en el que encontramos diálogos "actuados", "reportados", "imaginados", "mediados por la prensa" y "ocupados", vale decir, diálogos que ocurren con la presencia de los participantes en situaciones concretas, entre un participante y un colectivo, o sin la necesidad de los participantes presentes como es el caso de las representaciones del diálogo (ver Bolívar 2018).

\section{Los cambios en el discurso populista venezolano}

El autoritarismo en Venezuela no es nuevo ya que ha estado presente en su historia (Arenas 20I2; Bolívar \& Kohn I999; Caballero 2003) y hasta 1998 se mantuvo dentro de ciertos límites. No obstante, a partir de 1999 esta situación cambió, como ya vimos en la sección dedicada al contexto político. El populismo autoritario militarista venezolano se construyó en un proceso de desinstitucionalización de la democracia, y su militarización (Rivas Leone 20I2), que podemos ilustrar de dos 
formas. Por un lado, en la manera en que se transformó el diálogo institucional entre I999 y $2014 \mathrm{y}$, por otro, identificando los cambios en los planos de la acción política (las estrategias políticas), la acción discursiva (los géneros, las relaciones interpersonales, las estrategias del discurso) y la acción lingüística (los recursos empleados).

\subsection{La desinstitucionalización de la democracia}

Este fenómeno se observó de manera muy clara en el cambio en los géneros institucionales, como el juramento de ley en la toma de posesión presidencial. Este género discursivo se transformó de un texto altamente ritualizado a un género más cercano al manifiesto o mitin político. En el ejemplo (I) se muestra el juramento, tal como se usó en Venezuela por más de 40 años durante la democracia representativa. Nótese que se trata de un texto breve, en forma de diálogo, estructurado en cuatro partes: pre-pregunta-pregunta-respuesta y declaración, con un tópico fijo (respetar las leyes) y con un solo propósito (legitimar a un Presidente-Electo en su cargo y obtener su compromiso formal de que cumplirá con sus deberes):

(I)

Presidente del Congreso: Presento a usted el saludo y las congratulaciones del congreso nacional en cuyo nombre voy a proceder a tomarle el Juramento de Ley. (23 palabras)

Ciudadano Carlos Andrés Pérez ¿jura usted cumplir los deberes del cargo de Presidente de la República y cumplir y hacer cumplir la Constitución y las leyes en el ejercicio de su mandato? (Aplausos). (32 palabras)

Carlos Andrés Pérez: Sí, juro (2 palabras)

Presidente del Congreso. Si así lo hiciéreis habrá cumplido con su deber, si no la patria, vuestra conciencia y Dios os lo demandarán (20 palabras) (Toma de posesión de Carlos Andrés Pérez 02.04.I989, segunda presidencia)

Basándome en estudios ya realizados en los que el corpus estuvo constituido por todos los juramentos de ley a partir de I999 cuando la interacción comenzó a cambiar (Bolívar 20I 5, 20I6, 20I 8), a continuación presento un resumen de los cambios en la parte correspondiente a las respuestas que dieron los presidentes Hugo Chávez y Nicolás Maduro en el micro-diálogo (entre el presidente del congreso y el PresidenteElecto) y en el macro-diálogo, vale decir, a través del tiempo. Como 
veremos a continuación, a partir de I 999 cambió el propósito y el valor del juramento, porque cambiaron sus funciones discursivas y políticas. El ejemplo (2) muestra el primer juramento de Hugo Chávez

(2)

Juro delante de Dios, juro delante de la Patria, juro delante de mi pueblo que sobre esta moribunda Constitución haré cumplir... impulsaré las transformaciones democráticas necesarias para que la República nueva tenga una Carta magna adecuada a los nuevos tiempos. Lo juro. (Primera Toma de posesión de Hugo Chávez, 2 de febrero de I999). (40 palabras)

En este juramento, Chávez introduce los primeros cambios que condujeron a la desinstitucionalización de la democracia. En su respuesta, irrespeta la Constitución sobre la cual está jurando (la llama moribunda), no completa el compromiso de hacer cumplir las leyes y, en cambio, se compromete a impulsar una nueva Constitución. El acto discursivo original de respetar la Constitución se transforma en una promesa política. Se incluye al pueblo, que es mencionado por primera vez en este tipo de juramento, y se intensifica el compromiso político por repetición (Juro, 4 veces).

El ejemplo 3 muestra el segundo juramento de Chávez, en lo que se llamó la "relegitimación de poderes" debido a que participó en elecciones para relegitimarse con la nueva Constitución aprobada en I999.

(3)

Juro delante de esta revolucionaria Constitución que lucharé sin descanso junto a nuestro pueblo para cumplir los mandatos de la Revolución Bolivariana que recoge la Constitución. (Segunda Toma de posesión de Hugo Chávez, I9 de agosto de 2000)

En esta ocasión, Chávez juró solamente una vez, pero con sus palabras dio a la Constitución el carácter de revolucionaria y la función de cumplir los mandatos de la revolución. Estos rasgos no están descritos en la nueva Constitución y, en consecuencia, tales funciones fueron de tipo inconstitucional ya que la revolución no estaba prevista legalmente. El vínculo afectivo con el pueblo, ya introducido en el juramento de I999, se mantuvo con "nuestro pueblo" que remite a "mi pueblo".

El ejemplo (4) corresponde al tercer juramento de Chávez cuando fue reelecto como Presidente en 2007. Ya había anunciado en el 2006 el Socialismo del Siglo 2 I como el nuevo sistema político para Venezuela y 
América Latina. Nótese la intensificación en todos los niveles: en longitud, en el valor dado a la Constitución (maravillosa), en la repetición del verbo jurar ( 77 veces), en su compromiso personal y político, en los testigos del juramento, en la determinación para llevar adelante el socialismo, aún a costa de su vida y la de otros (Patria, socialismo o muerte). Chávez se construye a sí mismo como héroe y hace suyo el juramento que hizo el Libertador Simón Bolívar en I 805 (no daré descanso a mi brazo ni reposo a mi alma). Su persona es equiparable a Cristo y a Bolívar como salvadores del pueblo.

(4)

Juro delante de esta Constitución, de esta maravillosa Constitución, juro delante de usted, juro por Dios, por el Dios de mis padres, juro por ellos, juro por mis hijos, juro por mi honor, juro por mi vida, juro por los mártires, juro por los libertadores, juro por mi pueblo y juro por mi Patria que no daré descanso a mi brazo, ni reposo a mi alma; que entregaré mis días y mis noches y mi vida entera en la construcción del socialismo venezolano, en la construcción de un nuevo sistema político, de un nuevo sistema social, de un nuevo sistema económico. Juro por Cristo, el más grande socialista de la historia, juro por todos ellos, juro por todos los dolores, juro por todos los amores, juro por todas las esperanzas que haré cumplir, que cumpliré con los mandatos supremos de esta maravillosa Constitución, con los mandatos supremos del Pueblo venezolano aun a costa de mi propia vida, aun a costa de mi propia tranquilidad ¡Patria, socialismo o muerte! Lo juro. (Tercera toma de posesión de Hugo Chávez, io de enero de 2007). (I70 palabras)

Esta respuesta fue precedida por la pregunta de la Presidenta del Congreso (por primera vez una mujer, ahora esposa de Maduro) quien cambió la estructura de la pregunta para incluir primero una extensa intervención (639 palabras), seguida de una secuencia de preguntas sobre su compromiso con el pueblo (el Soberano) antes de hacer la pregunta de rigor sobre la Constitución. Igualmente, la declaración después de la respuesta sufrió cambios en longitud y propósito. Como puede observarse en el ejemplo (4) arriba, el compromiso de cumplir con la Constitución pierde credibilidad $^{6}$ con el slogan Patria, Socialismo o Muerte.

${ }^{6}$ La credibilidad puede constatarse internamente en el texto, mediante contradicciones semánticas o pragmáticas, y socialmente a través de la reacción de las personas frente a las afirmaciones (ver Bolívar 2012). 
El ejemplo (5) presenta el primer juramento de Nicolás Maduro como presidente interino a raíz de la muerte de Chávez, quien falleció en marzo de 2013, después de haber ganado elecciones nuevamente en octubre de 20I2. Su nombramiento como interino fue tema de candentes debates y protestas porque, de acuerdo con la Constitución, le correspondía el cargo al Presidente del Congreso ${ }^{7}$. Esta vez el presidente del Congreso era un militar y diputado (Diosdado Cabello), quien usó la parte correspondiente a la pregunta para realizar un mitin político en el que se reforzó el militarismo, el socialismo, y la diferencia con "la derecha". Maduro siguió los pasos del expresidente Chávez y reforzó el discurso Chavista en cuanto al rescate de la identidad originaria y su compromiso con el pueblo, y juró su lealtad absoluta con el Comandante Chávez. El compromiso de cumplir con la Constitución sigue siendo no creíble porque la Constitución no permite a los militares participar en política. La expresión "mano dura" apunta hacia la mano de la fuerza militar sobre los civiles y, por consiguiente, se incumple con la definición de democracia. Nótense dos señales lingüísticas importantes: primero, el trato de "compañero" y "hermano", que quita toda la solemnidad y formalidad al acto de juramentación e indica los lazos políticos y personales que unen a Cabello y Maduro, y el uso de "cumpliremos" y "haremos cumplir" para asumir el compromiso. En estos verbos se encuentra implícito un nosotros excluyente porque se refiere solamente al colectivo revolucionario y deja afuera al resto del pueblo que no es socialista.

(5)

Diputado compañero y hermano, Juro a nombre de la memoria heroica de nuestros pueblos indígenas, de Guaicaipuro, de nuestros libertadores, y el más grande de ellos Simón Bolívar, de Ezequiel Zamora y su ejército de desarrapados, Juro a nombre de nuestros niños, de nuestras niñas, de los soldados de la patria, de los obreros, de los campesinos, Juro a nombre de la lealtad más absoluta al Comandante Hugo Chávez que cumpliremos, que haremos cumplir esta Constitución bolivariana con la MANO DURA de un pueblo dispuesto a ser libre, lo JURO. (90 palabras) (Nicolás Maduro Moros, 8 de marzo de $20 \mathrm{I} 3$ (como presidente encargado). (92 palabras)

7 Chávez ganó las elecciones en octubre de 20I2, pero el 8 de diciembre se fue a Cuba a seguir su tratamiento contra el cáncer. Le correspondía juramentarse en enero de 2013 y no pudo hacerlo. Esto agudizó el conflicto. 
El ejemplo (6) corresponde a la respuesta de Nicolás Maduro como Presidente Constitucional, después de ganar por escaso margen las elecciones presidenciales contra Henrique Capriles, quien también había sido contrincante de Chávez. Esta vez se intensificó el compromiso con el pueblo, con el "Comandante Supremo" y con el socialismo. Por lo tanto, en este momento el juramento ya perdió totalmente el valor y propósito original de defender la Constitución y las leyes de la República (en la que había alternancia y pluralidad de ideas). La referencia a la "Constitución aprobada por el pueblo" fue una estrategia retórica para enfatizar que fue escogido legalmente y hacer frente a las críticas que ponían en duda la legitimidad de su candidatura y la transparencia de las elecciones.

(6)

Lo juro delante de esta Constitución aprobada por el pueblo en I999. Lo juro hoy ig de abril, por el legado eterno de los Libertadores. Lo juro por Dios, por Cristo Redentor, en él y por él, lo juro por el pueblo de Venezuela, lo juro por la memoria eterna del Comandante Supremo que cumpliré y haré cumplir esta Constitución y las leyes de la República en todo lo inherente al cargo de Presidente de la República Bolivariana de Venezuela, para construir una patria de felicidad, independiente y socialista para todos y para todas. ¡Lo juro! (Toma de posesión Nicolás Maduro, I9 de abril de 2013 (Presidente constitucional). (96 palabras).

Como ha podido observarse en este breve resumen solamente de las respuestas en el Juramento de Ley, las palabras empleadas por los propios actores políticos indican el cambio de una democracia representativa a una no-democracia que impone de manera autoritaria una forma de gobernar y una sola línea de pensamiento. Impone también el culto exacerbado a la personalidad y sacraliza la política.

\subsection{Las estrategias políticas y discursivas}

En la sección anterior vimos cómo el diálogo institucional pasó paulatinamente a ser anti-dialogicista a partir de 1999 porque, a pesar de defender un proyecto revolucionario para el pueblo, se legitimó la violencia y la muerte de quienes no forman parte de ese pueblo socialista. En lo que sigue, resumiré muy brevemente, las estrategias políticas y discursivas más relevantes extraídas de diferentes corpus recogidos con diferentes propósitos, en diferentes momentos, con géneros discursivos 
heterogéneos (discursos, noticias, propaganda, entrevistas, declaraciones, etc.) analizados con métodos variados (análisis manual y computacional, encuestas, etc.).

\section{i) La desinstitucionalización de la democracia}

La primera estrategia política del populismo autoritario chavista fue la desinstitucionalización de la democracia como sistema político, como mostramos en la sección anterior. Pudimos ver las estrategias con cierto detalle, aunque para tener el cuadro general es conveniente leer los textos completos (ver Bolívar 20I 5, 20I6, 20I 8). Pudimos observar la contradicción entre decir y hacer con el lenguaje, porque aunque se dice que se defiende la Constitución, no se la aplica ya que se violan principios fundamentales sobre el papel de los militares y el derecho a la vida. En otros estudios llevados a cabo con los métodos de la lingüística de corpus he mostrado que en el discurso de Hugo Chávez "democracia" está claramente asociada con "democracia revolucionaria” y no con democracia "representativa” (Bolívar 2009).

\section{ii) La polarización política}

La polarización política fue objetivo y método de la revolución. Esto se manifestó discursivamente en la división entre revolucionarios y no revolucionarios, bolivarianos y no bolivarianos. Además, en el propio discurso del Presidente Chávez se marcó la diferencia mediante diversos recursos lingüísticos que ubicaron a la población en dos bandos antagónicos (patriotas, anti-patriotas, revolucionarios- antirevolucionarios, socialistas-imperialistas). Esto se expresó en la oposición nosotros versus ellos, acompañada de valoraciones positivas para nosotros y negativas para ellos, tanto para la gente de Venezuela como de América Latina, con una retórica amenazante en la que predominaban las advertencias y las amenazas (Montero 2002). El yo y el ustedes cobró especial relevancia en el diálogo entre Chávez y el pueblo chavista (Bolívar 2013).

\section{iii) La hegemonía comunicacional}

Este fue para Chávez un punto clave y sigue siéndolo para Nicolás Maduro. La estrategia de Chávez consistió en neutralizar todos los medios de Oposición, dificultar la tarea de quienes fueran disidentes, y crear nuevos medios para difundir la revolución, como Telesur. Al mismo tiempo, mantuvo el contacto directo con el pueblo a través de su Programa Aló Presidente, que se transmitía todos los domingos en cadena nacional por radio y televisión. A eso se suman las alocuciones 
presidenciales, las llamadas a la radio y a la televisión, su presencia activa en distintos eventos y, sobre todo, las cadenas nacionales que podían hacerse en cualquier momento por diferentes motivos. Maduro ha fortalecido esta hegemonía.

\section{iv) La vinculación afectiva}

Esta fue posiblemente la mayor estrategia política-discursiva de Chávez porque profundizó la polarización en función de dos polos afectivos que la alimentaron. Por un lado, la vinculación afectiva positiva con el pueblo y negativa con sus "enemigos”. Él se construyó como "el corazón de la patria" y "el corazón del pueblo" que defendía y protegía al pueblo de los "imperialistas", "oligarcas”, "burgueses”, “fascistas” (Bolívar 2013, 20I 5, 20I 6, 20I8). Fue el amor exacerbado por el pueblo lo que lo convirtió en héroe y mártir de la revolución (ver Paz 20I4), y en la encarnación del pueblo ("Tú también eres Chávez”, “Todos somos Chávez”). Su vinculación con el pueblo estuvo basada en una reinterpretación de la historia, el recurso constante a la heroicidad del pueblo que se liberó de la dominación española. Mientras que la relación con el adversario se basó en el desconocimiento de su existencia y en el desprecio como interlocutor (“cipayos", "vende patria”, “el majunche”, "la nada”).

\section{v) La manipulación de las emociones por el miedo}

Esta es una estrategia que se usa en la política de manera bastante frecuente (Wodak 20I5), pero que adquiere rasgos de manipulación "ilegítima" (van Dijk 2006) cuando se practica para favorecer los intereses personales del manipulador. El miedo fue empleado particularmente para mantener la revolución con el argumento del magnicidio (el presidente está en peligro), del ataque de fuerzas extranjeras (una invasión), la pérdida del petróleo, y la pérdida de los logros alcanzados por la revolución, particularmente en relación con trabajo, vivienda, salud (Bolívar 20I3). El miedo se usó para controlar al pueblo y también a los opositores ("Esta es una revolución pacífica, pero armada", "Patria, Socialismo o Muerte") y a los traidores a la revolución ("Los traidores irán al basurero"). El discurso preferido para estos propósitos fue el de la hipoteticalidad, manifestada en la gramática del irrealis, por ejemplo con el uso de subjuntivos y formas condicionales como en "Si la burguesía volviera a ganar, Venezuela se volvería a hundir" (Bolívar 20I4), y el discurso militarizado expresado en metáforas bélicas que solo conciben la política como guerra entre dos bandos enfrentados (Duarte 2013; Molero de Cabeza 2009). 
Durante el mandato de Maduro, el miedo y el desprecio al otro han sido profundizados mediante nuevas estrategias, particularmente la burla y la humillación, especialmente de Trump, otros jefes de estado, participantes en marchas de protestas, y presos políticos ${ }^{8}$. Igualmente, el miedo a la muerte de los presos políticos se ha incrementado, como en un caso reciente en que, estando detenido, un preso se lanzó desde un décimo piso. Esta acción fue reportada por el gobierno como un "suicidio", el cual fue puesto en duda por los medios nacionales e internacionales y por la ciudadanía'. Por su parte, al igual que Chávez en su momento, Maduro ha recibido de los venezolanos una gran cantidad de insultos, burlas y señales de menosprecio (como llamarlo "Maburro" en vez de Maduro).

vi) Legitimación de la violencia verbal y física

La violencia ha formado también parte de la política venezolana, pero en la revolución bolivariana se legitimó desde el poder, tanto la violencia verbal como la física. La agresión verbal, manifestada primero como una descortesía estratégica (el caso de "la moribunda" constitución) cuyo objetivo era llamar la atención hacia un cambio (Bolívar 2007a), se transformó luego en un tipo de "anti-cortesía” similar a la propuesta por Zimmerman (2005) en el caso de la interacción entre jóvenes masculinos en la construcción de su identidad de grupo. Pero, a diferencia de los jóvenes, quienes violando normas y reglas colaboran mutuamente para construir un "universo anti-normativo" que les garantice ser respetados (p. 265), en la anti-cortesía política puesta en práctica por Chávez y continuada por Maduro, se impuso un estilo que no es compartido por todos, y eso ha generado mayor violencia verbal y física. El Presidente Chávez usó el insulto como estrategia política para disminuir al contrario y, eventualmente, hacerlo salir del ruedo político. Sus insultos están registrados ${ }^{\text {Io }}$ y muestran que fue una

${ }^{8}$ Véase por ejemplo con referencia a un diputado opositor encarcelado por supuesta participación en supuesto atentado a Maduro: Maduro se burló de su aspecto en la prisión. https://wwww.infobae.com/ i I de agosto de 2018 . Consultado el 22 de octubre de 2018.

9 Véase por ejemplo: Fiscalía venezolana informa del "suicidio" del concejal...DW. https://www.dw.com.es/fiscalia.venezolana...de suicidio...maduro/a-45805907 $8 \mathrm{de}$ octubre de 2018 . Consultado el 22 de octubre de 2018.

ro Véase, por ejemplo, "Lista de insultos Chávez Parte III. Un 2012 que va desde hipócritas, apátridas, etc., etc.”, http://www.marthacolmenares.com/2012/02/I6/ lista-de-insultos-chavez-parte.iii-que.ave-desde-hipocritas-apatridas-etc-etc Consultado el I 6 de febrero de 2012 
acción intencional selectiva, vale decir, los "targets" o destinatarios de los insultos fueron escogidos de acuerdo con fines políticos (Bolívar 20I8). Las violaciones recurrentes de normas de trato en la interacción política, particularmente los insultos a quienes eran percibidos como "enemigos", sirvieron como catalizadores de la polarización y de la violencia física, y también profundizaron las diferencias y el odio. El diálogo, como parámetro para medir la calidad de la democracia, ha sufrido un daño extremo hasta el punto de que ha quedado como un tópico del discurso, algo de lo que se habla, pero no como encuentros entre personas que se reconocen y respetan. Las esperadas señales de cooperación entre las partes todavía no se vislumbran (Bolívar 2008, 2009b, 20I2).

\section{Conclusiones}

En este trabajo hemos resumido la forma en que se construyó discursivamente el populismo autoritario militarista venezolano en su acción política. Nuestro objetivo fue mostrar que los populismos radicales son "incluyentes" en teoría porque, supuestamente, toman en cuenta al pueblo, entendido como el sector más desfavorecido o descuidado de la población, pero son a la vez excluyentes porque no reconocen a quienes no estén de acuerdo con la línea ideológica adoptada. Nuestra investigación muestra que, en la práctica, en el caso de la cultura política venezolana, el pueblo también es excluido porque no tiene voz ni participación sino como beneficiario de dádivas o regalos. Cuando los fondos se acaban, como ocurrió en Venezuela en el cambio de Chávez a Maduro, el programa político falla porque no se ha construido un verdadero diálogo democrático con el pueblo como totalidad. Nuestro análisis muestra que el anti-diálogo como práctica política basada en la polarización y en el conflicto, tal como se presentó en Venezuela a partir del arribo de Chávez, y reforzado por Maduro, no es recomendable para la convivencia democrática.

El análisis interaccional del discurso, que mostré de forma muy breve, tiene ventajas que no presentan otros enfoques en los estudios críticos del discurso, por lo que puede considerarse una posición post-fundacional. En primer lugar, se propone un cambio de foco de "los textos en contexto a la gente en eventos" (Bolívar 2018) para poder identificar a los responsables del cambio político y la forma en que los actores políticos usan el lenguaje para unir o dividir a los participantes en el diálogo que da vida a la política y que es sinónimo de libertad. En segundo lugar, el hecho de enfocarnos en los participantes y en el diálogo, como 
categorías clave desde una perspectiva sincrónica y diacrónica, nos permite diferenciar entre "las voces" en el texto, que es un tipo de diálogo centrado en el texto, y el diálogo social y político, que se construye en la lucha política, en la interacción entre todos los que mueven y motivan los cambios, vale decir, los responsables de la calidad del diálogo y de su propio destino político. Finalmente, desde mi perspectiva, centrarse en el diálogo significa un compromiso teórico porque los significados se construyen en la interacción, un compromiso metodológico por la forma en que se recogen los datos a medida que tienen lugar los eventos, y un compromiso con la responsabilidad de vivir porque se trata de reconocer el diálogo y el estado de derecho como garantías de la supervivencia de la especie humana (Bolívar 20I0).

\section{Referencias}

Arenas, N. (2007). "Poder reconcentrado: el populismo autoritario de Hugo Chávez". Revista Politeia, 39 (30), 23-63.

Arenas, N. (20I2). "La Venezuela rentista. Imaginario político y populismo". Cuadernos del CENDES 29 (80). I37-I 45.

Arendt, H. (1958). The human condition. Chicago and London: The University of Chicago Press.

Bobbio, N., Matteucci, N., \& Pasquino, G. (eds.). (2000). Diccionario de política. México/España: Siglo XXI editores.

Bolívar, A. (2007a). "El análisis interaccional del discurso: del texto a la dinámica social”, en A. Bolívar (ed.), Análisis del Discurso. Por qué y Para qué. Caracas: Los Libros de El Nacional, 249-277.

Bolívar, A. (2007b). "Dialogue and confrontation in Venezuelan political interaction", en T. A. Van Dijk (ed.), Major works in discourse studies. Los Angeles, London, New Dehli, Singapore: Sage Publications I, 26I-274.

Bolívar, A. (2008). “'Cachorro del Imperio' versus 'cachorro de Fidel”: los insultos en la política latinoamericana. Discurso y Sociedad 2(I), I-38.

Bolívar, A. (2009a). “'Democracia' y 'revolución”” en Venezuela: un análisis crítico del discurso político desde la lingüística de corpus. Oralia, I 2, 27-54.

Bolívar, A. (2009b). “¿Por qué no te callas?”: los alcances de una frase en el (des)encuentro de dos mundos. Discurso y Sociedad, 2 (I), 87-I I 5.

Bolívar, A. (20I0). "Dialogue in the dynamics of political practice", en D. Koike \& L. R. Alfano (eds.), Dialogue in Spanish. Studies in functions and 
contexts. Amsterdam/Philadelphia: John Benjamins Publishing Company, I $59-$ I 88 .

Bolívar, A. (20I 2). "Political apologies by heads of state in diplomatic conflicts: between sincerity and political cynicism", en S. Cantarini (ed.), Dialogue: state of the art. Studies in memory of Sorin Stati. München: Lincom Academic Publishers, 89-104.

Bolívar, A. (2013). "La construcción discursiva de la revolución bolivariana: polarización y manipulación en la campaña electoral de 2012". Temas de coyuntura $67, \mathrm{I} 3 \mathrm{I}-\mathrm{I} 63$.

Bolívar, A. (20I4). “'Si la burguesía volviera a ganar, Venezuela se volvería a hundir': la hipoteticalidad como estrategia en el discurso político". Revista de Filología 32, 45-6I.

Bolívar, A. (20I 5). "A afectividade no discurso populista”, en G. Lara \& L. R. d. Cássia (eds.), Discurso e (des)igualdade. São Paulo: Contexto, I43-I60.

Bolívar, A. (20I6). "El discurso de la afectividad en la interacción política", en A. M. Hernández, M. E. Muriel, B. H. Muñoz-Cobo, \& J. L. López (eds.), Oralidad y análisis del discurso. Homenaje a Luis Cortés Rodríguez. Almería: Universidad de Almería I-I9.

Bolívar, A. (201 8). Political discourse as dialogue. A Latin American Perspective. London and New York: Routledge, Taylor \& Francis Group.

Bolívar, A. y Kohn, C. (I999). "Diálogo y participación. ¿cuál diálogo? ¿cuál participación?”, en A. Bolívar \& C. Kohn (eds.), El discurso político venezolano. Un estudio multidisciplinario. Caracas: Universidad Central de Venezuela, I03-I I 5 .

Caballero, M. (2003). Gómez, un tirano liberal. Caracas: Alfadil Ediciones.

Charaudeau, P. (2000). "Une problématisation discursive de l'émotion. A propos des effets de pathémisation à la télévision”, en C. Plantin, M. Marianne, \& V. Traverso (eds.), Les émotions dans les interactions. Lyon: Presses Universitaire de Lyon, I25-I 55.

Charaudeau, P. (2009). "Reflexiones para el análisis del discurso populista". Discurso y Sociedad 3(2), 253-279.

Chilton, P., \& Schäffner, C. (2002). "Introduction. Themes and principles in the analysis of political discourse", en P. Chilton \& C. Schäffner (eds.), Politics as text and talk. Amsterdam/Philadelphia: John Benjamins, I-4I.

Chumaceiro, I. (2003). "El discurso de Hugo Chávez: Bolívar como estrategia para dividir a los venezolanos”. Boletín de Lingüística 20, 22-42.

Chumaceiro, I. (20I0). "El discurso de Hugo Chávez. Del poder de la seducción a la confrontación como estrategia”, en F. Ramos, C. Romero \& H. Ramírez 
(eds.), Hugo Chávez: una década en el poder. Bogotá: Editorial Universidad del Rosario, 21 5-237.

De la Torre, C. (2007). "The resurgence of radical populism in Latin America”. Constellation I4 (3), 384-397.

De la Torre, C. (2010). Populist seduction in Latin America: The Ecuadorian experience. Athens OH: Ohio University Centre for International Studies. Primera edición en 2000.

De la Torre, C. (20I6). "Populism and the politics of the extraordinary in Latin America”. Journal of Political ideologies 2I(2), I 2 I-I39.

Duarte, M. (2013). "Redes de metáforas cognitivas en el discurso político: 'el socialismo del siglo XXI' de Hugo Chávez”. Revista Latinoamericana de Estudios del Discurso I $3(\mathrm{I})$, 57-77.

Fairclough, N. (2000). "Dialogue in the public sphere”, en S. Sarangi \& M. Coulthard (eds.), Discourse and social life. London: Longman: I70-1 84 .

Fairclough, N. (2003). Analysing discourse. Textual analysis for social research. London and New York: Routledge.

Madriz, M. (2008). "Pathos, violencia e imaginario democrático". Akademos I, IO5-I 60

Mainwaring, S. (2012). "From representative democracy to participatory competitive authoritarianism: Hugo Chávez and Venezuelan politics". Perspectives on politics Io (4), 955-967.

Mires, F. (20I4). Prologue, in A. Chaplin (20I4), Chavéz's legacy: The transformation from Democracy to a Mafia State. Maryland: University Press of America, i-ix.

Moffit, Benjamin (2015). "Populism and democracy: friend or foe? Rising stars deepen dilemma", in https://theconversation.com/populism-and-democracy-friend-or-foe-rising-stars.deepen.dilemma-39695 Consultado el 22 de agosto de 2016

Moffit, B. (20I6). The global rise of populism. Performance, political style, and representation. Stanford: Standford University.

Molero de Cabeza, L. (2009). "La metáfora en el discurso político venezolano”, en M. Shiro, P. Bentivoglio, \& F. D. Erlich (eds.), Haciendo discurso. Homenaje a Adriana Bolivar. Caracas: Universidad Central de Venezuela, $305-332$.

Montero, M. (2002). "Militarización de la política, politización de los militares: un análisis psicopolítico”, en L. Molero de Cabeza \& A. Franco (eds.), El discurso politico en las ciencias humanas y sociales. Caracas: Fonacit, I 59-I73. 
Mouffe, Ch. (2016). "In defence of left-wing populism", https://Sidney democracynetwork.org/article-defence-leftwing-populism Consultado el i 8 de agosto de 2016.

Nieto y Otero, M. (2007). “Discurso y efectividad”, en A. Bolívar (ed.), Análisis del discurso. ¿Por qué y para qué? Caracas: Los Libros de El Nacional y Universidad Central de Venezuela, 87-I I7.

Nieto y Otero, M. (2012). Afectividad en el discurso político. Estrategias pragmalingüísticas para la vinculación afectiva en el discurso político oral. Saarbrucken: Editorial Académica Española.

Paz, Y. (20I4). “El Presidente está enfermo ¿Qué tendrá el Presidente?: La enfermedad y sus metáforas en el discurso de Hugo Chávez Frías”. Discurso $y$ Sociedad 8(2), 299-325.

Petkoff, T. (2005). “Las dos izquierdas”. Nueva Sociedad, I97, I I4-I 29.

Pino Iturrieta, E. (2003). El divino Bolivar. Ensayo sobre una religión republicana. Madrid: Catarata.

Rivas Leone, J.A. (20I2). "La experiencia populista y militarista en la Venezuela contemporánea”. ICPS Working Paper 37. Institute de Ciènces Politiques i Socials. https://www.icps.cat/archivos/workingpapers/wp307. pdf? $\operatorname{nog} a=I$

Van Dijk, T. A. (I993). "Principles of critical discourse analysis". Discourse \& Society 4 (2), 249-283.

Van Dijk, T. A. (2002). "Political discourse and political cognition", en P. Chilton \& C. Schäffner (eds.), Politics as text and talk. Analytical approaches to political discourse. Amsterdam / Philadelphia: John Benjamins, 203-237.

Van Dijk, T. A. (2005). "Contextual knowledge management in discourse production. A CDA perspective”, en R. Wodak \& P. Chilton (eds.), A new agenda in (critical) discourse analysis. Amsterdam: John Benjamins, 7 I-Ioo.

Van Dijk, T. A. (2006). "Discourse and manipulation”. Discourse \&o Society I $7(3), 359-383$.

Wodak, R. (200ra). "What CDA is about. A summary of its history, important concepts and its development”, en R. Wodak \& M. Meyer (eds.), Methods of critical discourse analysis. London: Sage Publications: I-I3.

Wodak, R. (200Ib). “The discourse-historical approach”, en R. Wodak \& M. Meyer (eds.), Methods of critical discourse analysis. London: Sage Publications, 63-94. 
Wodak, R. (2015). The politics of fear. What right-wing populist discourses mean. Los Angeles, London, New Dehli, Singapore, Washington DC: Sage.

Zimmermann, K. (2005). “Construcción de la identidad y anticortesía verbal”, en D. Bravo (ed.), Estudios de la (des)cortesía en español. Categorías conceptuales y aplicaciones a corpora orales y escritos. Estocolmo-Buenos Aires: Edice y Editorial Dunken, 244-27. 
